\title{
Um imaginário ativo na cultura nacional*
}

\section{RESUMO}

O texto aponta, dentre outras questões, que não há no Brasil ativos pesquisadores do imaginário. Talvez isso se deva à dificuldade em separar real de imaginário num país de longa tradição patrimonialista, pois, como bem se sabe, a cultura patrimonial apela fortemente para o imaginário da família ampliada em seu movimento de preservação e transmissão do capital. Ou esteja relacionado aos vários tipos de imaginário social que concorrem para constituir relações sociais originalíssimas no nível das formações populares. Isso faz com que o imaginário como substantivo esteja sempre demandando permanentemente algum esforço conceitual em nossa paragem.

\section{PALAVRAS-CHAVE}

imaginário ativo

cultura nacional

cultos afro-brasileiros

\section{ABSTRACT}

The article stresses, among other issues, that there are no active researchers of the imaginary in Brazil. Perhaps that is due to the dificulty to part reality from imaginary in a country with a long tradition of cultural pratrimonialism, since, as we know it, patrimonial culture reaches out strongly to the idea of family broaden by a movement to preserve and transmit assets. Or maybe it is related to the many types of social imaginary that dispute to construct original social relations in popular formations. That makes the imaginary as a substantive always demanding some conceptual effort of our side.

\section{KEY WORDS}

active imagination

national culture

african-brazilian cults
Eu gostaria de começar minha intervenção neste encontro sobre o imaginário com uma remissão ao conto "Um posto avançado do progresso", texto que serviu de ensaio para Joseph Conrad escrever depois a obraprima novelística que é "Coração das Trevas" - um dos maiores libelos anticolonialistas do século XX. Minha remissão contempla o trecho em que dois agentes coloniais expressam indignação ao descobrirem que alguns de seus empregados africanos foram vendidos a traficantes de escravos. Um deles diz: "A escravidão é uma coisa horrível". E o outro: "Terrível, tanto sofrimento".

Mas Conrad é cáustico para com toda essa piedade: "Acreditavam no que diziam. Qualquer pessoa demonstra uma deferência respeitosa perante certos sons que ela própria ou os seus semelhantes são capazes de emitir. Quanto aos sentimentos, porém, ninguém na verdade sabe nada. Falamos com indignação ou entusiasmo, falamos de opressão, crueldade, crime, devoção, sacrifício, virtude, e não sabemos o que existe de real por trás das palavras. Ninguém sabe o que significa o sofrimento ou o sacrifício - exceto, talvez, as vítimas da finalidade misteriosa dessas ilusões".

O novelista está deixando ver o quanto pode haver de enganoso na simples relação da empatia com a linguagem. Indignação e entusiasmo são conotados como emoções que desencadeiam palavras, mas que podem constituir grandes barreiras para o acesso ao que realmente importa e leva à ação, isto é, as emoções lúcidas ou sentimentos. Não se fala sem linguagem, mas há de fato muita ilusão encobridora na mediação entre homem e mundo operada pela ordem simbólica. O sentimento, o mito, a iluminação interna (o lumen naturale, de que fala Peirce) são formas de apreensão do mundo que elidem as barreiras da mediação. São formas primordiais da ordem imaginária.

\section{0 imaginário como substantivo}

Com uma única exceção conhecida, não há no Brasil ativos pesquisadores do imaginário. Talvez isso se deva, por um lado, à dificuldade em separar real de imaginário num país de longa tradição patrimonialista, pois, como bem se sabe, a cultura patrimonial apela fortemente para o imaginário da família ampliada em seu movimento de preservação e transmissão do capital. Por outro lado, vários tipos de imaginário social concorrem para constituir relações sociais originalíssimas no nível das formações populares.

Mas o imaginário como substantivo está sempre demandando algum esforço conceitual. Num livro ainda recente (As Estratégias Sensíveis), pudemos nos debruçar sobre esse conceito, mostrando que filósofos, antropólogos, psicólogos e escritores sempre 
foram atraídos pelas forças espirituais de produção de imagens, normalmente enfeixadas no conceito de "imaginação", a vis imaginativa, que os escolásticos entendiam como o sentido interno capaz de conservar o traço dos objetos percebidos, representados sob a forma de imagens. Para os modernos, além da reprodução de percepções passadas (que alguns preferem reservar exclusivamente à memória), a imaginação implica principalmente o poder de criar ficções, combinando as imagens do passado em novas sínteses.

Sejam oriundos da experiência afetiva das formas ou da matéria, os produtos da imaginação constituem um repertório individual ou coletivo de imagens, a que se dá o nome de imaginário. $\mathrm{O}$ termo ganha sentido na separação disjuntiva com o princípio de realidade, operada pelo racionalismo da cultura ocidental. Peirce prefere evitá-lo, optando por categorias fenomenológicas que abrangem três modalidades da experiência semiótica. A primeira, a que chama de Firstness (primeiridade) - relacionada às noções de acaso, indeterminação e possibilidade - diz respeito ao universo do possível, onde tudo é espontâneo e original, guiado pelo livre curso da imaginação․

$\mathrm{Na}$ teoria psicanalítica, o imaginário refere-se a "processo primário", o modo inconsciente de funcionamento do psiquismo, cuja manifestação mais evidente é o sonho. De modo mais categórico na teoria lacaniana, imaginário é um efeito necessariamente decorrente do fato da constituição do sujeito do desejo. Em termos muito simplificados, pode-se dizer que todo processo de simbolização desenrola-se entre um limiar mínimo de abertura entre natureza e consciência (o imaginário) e um limiar amplo de realização, que é a relação social identificada com a linguagem e, portanto, já dentro da diferença essencial entre matéria e psiquismo.

No imaginário, há o nível primordial dos fantasmas ou fantasias e aquele que Bachelard chamava de imaginação material, ou seja, as imagens já dadas em sua articulação com a organização simbólica. O tópico da imaginação criativa é recorrente nos estudos sobre a produção poética. Bachelard distingue duas imaginações: "uma imaginação que dá vida à causa formal e uma imaginação que dá vida à causa material ou, mais brevemente, a imaginação formal e a imaginação material" ${ }^{2}$. As imagens da forma, mais trabalhadas pela psicologia da imaginação (formas conscientes ou inconscientes) ou pela estética, são as que decorrem de uma causa interna, sentimental. As outras, saídas diretamente da matéria (a água, o fogo, o espaço, a pedra, etc.) têm uma causa "substancial" ou material.

À imaginação material, Bachelard dedicou várias de suas luminosas análises. Mas fez a ressalva de que, numa obra poética, a primeira sedução do leitor é a da beleza formal, em que detém o primado, o sentimento da alegria pelo contato com a variedade das formas:
“Em razão dessa necessidade de seduzir, a imaginação trabalha geralmente na direção da alegria - ou pelo menos na direção de uma alegria! - no sentido das formas e das cores, no sentido das variedades e das metamorfoses, no sentido de um futuro da superfície"3.

\section{Sejam oriundos da experiência} afetiva das formas ou da matéria, os produtos da imaginação constituem um repertório individual ou coletivo de imagens,
a que se dá o nome de imaginário

Bachelard e os psicanalistas raciocinam aqui em registros bastante diferentes. Para a psicanálise, o importante é demonstrar que a identificação imaginária, ou identificação com a imagem de um semelhante (identificação narcísica, no vocabulário de Freud) caracteriza o "eu", ou seja, a formação do inconsciente que desconhece a causa de sua própria constituição ou de sua condição produtiva, dando assim margem ao funcionamento da estrutura inconsciente. Esse registro ou matriz gerativa é o lugar privilegiado dos complexos e das fantasias.

A psicanálise freudiana herda e tenta afastar-se da dicotomia cartesiana entre ilusão e realidade, a mesma que levou a civilização contemporânea a separar radicalmente da vida onírica a vida real. Mas essa tentativa está longe do senso comum e, até mesmo do pensamento social, que costuma entender o imaginário como outro termo, além da realidade: “Na partição homem/natureza, a natureza (objetiva, material) é apenas o imaginário do homem assim conceituado. Na partição sexual masculino/feminino, distinção estrutural e arbitrária que funda o princípio de "realidade" (e de repressão) sexual, a "mulher" assim definida é sempre apenas o imaginário do homem. Cada termo da disjunção exclui o outro, que se torna o seu imaginário" 4 .

O outro termo da disjunção é, portanto, sob a hegemonia do logos, matéria de desejo, sonho, devaneio e mito, como assinala Charles Rodier: "O mapa do mundo imaginável só é traçado nas fantasias. O universo sensível é infinitamente pequeno" ${ }^{5}$.

$\mathrm{Na}$ cultura ocidental, o imaginário resulta primordialmente de uma imaginação ativa que leva criadores e contempladores a participarem conjuntamente da circulação das formas sensíveis ${ }^{6}$. A sua valorização por poetas e artistas fez-se sempre acompanhar, entretanto, de uma profunda desconfiança por parte do senso comum, para quem 
a imaginação era freqüentemente encarada como la folle du logis, isto é, "a louca da casa", aquela que se mantinha acorrentada nos fundos da residência burguesa.

Em certos casos, porém, os próprios criadores manifestaram a sua desconfiança para com o excesso de imaginário - entendido tanto como superexcitação intelectual quanto como descaminho da imaginação ou abuso do inconsciente - na produção artística. Um bom exemplo francês é Balzac, que vituperava contra "a abundância grande demais do princípio criador", mortal para a execução da obra, em sua opinião. Outro exemplo é o alemão Hoffmann, para quem o desbordamento intelectual e imaginativo seria capaz de tornar o homem cego ao mundo natural. Comenta um crítico: "O que faz Nathanel perder-se em O Homem de Areia é que ele não é mais capaz de distinguir um ser humano vivo de sua cópia artificial (a boneca Olympia)"7.

\section{0 que antes pensadores e poetas chamavam de imaginário é} agora, graças aos recursos da informática, a matéria corrente de um fluxo informacional capaz de produzir infinitamente formas sonoras, visuais, táteis, sem que o resultado possa ser concebido como outro termo ou outra margem, separada do real

Orealista BalzaceoromânticoHoffmann, duasfiguras exponenciais da literatura européia, movem-se aí no interior de uma temática que reflete as preocupações com os limites entre a vida e a arte, com o desgaste da vitalidade humana em virtude da superabundância de recursos intelectuais ou imaginativos. Hoje o conflito desloca-se para os limites entre a vida "nua" e suas cópias, artificialmente produzidas por uma tecnologia que se estende da manipulação genética à produção de uma realidade virtual mediante dispositivos de informação e comunicação.

Com efeito, é forçoso pensar hoje a imagem a partir de seu novo estatuto cognitivo, que advém de sua captura pela ordem do audiovisual no bios midiático, onde predominam os ícones e os índices, indutores de identificação e projeção, principais formas de participação imaginária do público; igualmente, da captura computacional, onde predominam os dígitos e os modelos submetidos ao cálculo. $O$ que antes pensadores e poetas chamavam de imaginário é agora, graças aos recursos da informática, a matéria corrente de um fluxo informacional capaz de produzir infinitamente formas sonoras, visuais, táteis, sem que o resultado possa ser concebido como outro termo ou outra margem, separada do real. A idealidade materializa-se no bios virtual, constituindo o próprio solo orgânico do novo tipo de sociabilidade emergente. Protegido pelo mercado, afastado da pura contemplação do objeto como se dava na dimensão representativa tradicional, $\mathrm{o}$ imaginário realiza-se tecnologicamente, confundindose com as representações humanas da vida real. Uma confusão que, no limite, pode significar a morte das ilusões humanas.

\section{Um caso de imaginário social}

Tal associação tecnológica entre imaginário e vida real difere radicalmente do modo com as sociedades antigas ou arcaicas viviam as experiências com a "outra margem", isto é, com a esfera do invisível, plena de entidades fantasmáticas, vivas e mortas, portanto, com algo que antropólogos e sociólogos chamariam hoje de "imaginário", mas que pode ser vivido como a realidade concreta disso que Edgar Morin chamou de "seres de espírito" - desde os deuses às idealidades matemáticas.

Esse tipo de imaginário pode constituir relações sociais originais. Para bem entender esta proposição, é preciso considerar, como Sercovich, que a força da dimensão imaginária na ordem dos discursos deve-se ao seu potencial de remissão direta à realidade ${ }^{8}$. Ou seja, enquanto que a ordem simbólica implica uma mediação entre o discurso e o mundo (que assim não se correspondem termo a termo) o imaginário passa por cima da mediação, zera a história e dá margem à constituição de possíveis. É assim que o imaginário social, não raro concebido como um estoque de representações congeladas, se transforma em imaginário ativo, coletivo e estratégico.

Vamos tomar como exemplo o caso dos cultos afro-brasileiros. As comunidades litúrgicas matriciais, aquelas que deram origem à profusão e à popularização desses cultos de origem africana, foram resultado de uma aglutinação elitista, caracterizada pela participação fundacional de altos dignitários e sacerdotes do milenar culto aos orixás, trazidos ao Brasil na condição de escravos, em conseqüência das guerras interétnicas e das incursões guerreiras dos escravagistas no Continente africano. A cidade-estado de Ketu, como se sabe, foi conquistada e arrasada pelo rei Ghezo, que vendeu levas de cativos aos portugueses. Mas a gente de Ketu, nagô, chega aqui sem moral de escravo, e sim de cativo com a linguagem muçulmana da jihad, da guerra. As insurreições não 
prosperaram, mas as elites negras ensaiaram outras formas de afirmação étnica.

No que diz respeito à comunidade litúrgica, convém usar o termo "religiosidade", já que não se trata de "religião" no sentido europeu de monopolização empresarial e universal da fé. É certo que Weber faz, aliás, uma distinção entre religiões rituais, religiões de redenção, religiões salvacionistas ou soteriológicas, mas leva em consideração especial o caráter monoteísta ou politeísta das crenças coletivas, sem ignorar que há religiões sem divindade (a exemplo do budismo). A palavra "religiosidade" relativiza os significados rígidos atribuídos à religião, já que comporta outras variáveis como práticas mágicas e, mesmo estratégias de liberação social. No caso dos cultos afrobrasileiros, trata-se mesmo de estratégias religiosomítico-históricas (religiões rituais, que cultuam tanto princípios cosmológicos ou orixás, voduns, inquices, etc. quanto os ancestrais, ou eguns) com o objetivo de assegurar a continuidade um agrupamento humano (os descendentes de africanos) nas condições adversas da diáspora escrava.

Esse tipo de estratégia fez com que, em torno da família-de-santo ou das comunidades litúrgicas de origem africana, popularmente conhecidas como candomblés, se criasse um modelo singular de organização social da gente negra. Foi isto que deu à cidade de São Salvador, por exemplo, o rosto e o espírito que a sustentam, os traços sempre visíveis da singularidade afro-baiana. Por isto também pode irradiar-se para outros territórios. Inexiste, como bem se sabe, um homogêneo paradigma africano: há quem fale de quarenta e cinco e, mesmo, cinqüenta "Áfricas" diferentes. Entretanto a diversidade das realidades sócio-econômicas e das tradições culturais converge para pontos paradigmáticos comuns, um dos quais é a atitude mística, chamada de "animismo" pelo racionalismo teológico do Ocidente, mas que de fato se trata da experiência do sagrado em sua radicalidade.

Convém, portanto, falar da religiosidade (e não de religião em seu sentido romano) ou dos cultos afrobrasileiros como uma "experiência" (no sentido que Walter Benjamin dá a essa palavra) de relacionamento ativo e coletivo de afro-descendentes com a História, tanto em sua forma manifesta (memória) como em forma latente (mitos, imaginário, transmissão intergeracional). Distingue-se, assim, da "vivência" religiosa, que é um relacionamento privado com o evento da transcendência. $\mathrm{Na}$ verdade, a religião como esfera da vida privada é uma astúcia liberal para resgatá-la diante do impasse de sua contradição com a política, modernamente destinada ao espaço público.

Os cultos afro-brasileiros atestam e continuamente confirmam a presença na História nacional de um complexo paradigma civilizatório, diferencialmente distante do paradigma europeu, centrado nos poderes da organização capitalista e da racionalidade sígnica.
Na cosmovisão desses cultos se colocam em primeiro plano o reconhecimento do aqui e agora da existência, as relações interpessoais concretas, a experiência simbólica do mundo, o poder afetivo das palavras e ações, a potência de realização das coisas e a alegria frente ao real.

Tudo isso decorre de um pacto simbólico - ou seja, uma rede de signos e de alianças legitimadoras do consenso intercultural (entre as diversas etnias de origem africana) e transcultural (negros com brancos) - historicamente estabelecido na conjuntura de formação da sociedade nacional. Nada disto pode ser entendido pela pura abordagem culturalista, uma vez que o pacto simbólico decorre de agir estratégico grupal. A estratégia está na mobilização dos recursos para a consolidação das alianças internas ao grupo e nas táticas de aproximação com a sociedade global hegemônica.

Na cosmovisão desses cultos se colocam em primeiro plano o reconhecimento do aqui e agora da existência, as relações interpessoais concretas, a experiência simbólica do mundo, o poder afetivo das palavras e ações, a potência de realização das coisas e a alegria frente ao real

Há um agir singular na transmissão patrimonial da liturgia negra. Nenhum patrimônio cultural socialmente operativo se transmite como um pacote inerte, um estoque de ativos dados para sempre, e sim como algo que é preciso reinserir na História presente, atribuindo-lhe novos contornos, revivificando-o. As heresias, os cismas, as dissoluções e os banimentos podem ser parte de uma dinâmica dessa natureza.

Aquilo que se transmite é o pacto simbólico em torno da Arkhé, isto é, um consenso quanto a poderes míticos e representações que se projetam na linguagem - atuada, proferida, cantada - do terreiro e nos modos afetivos (fé, crenças, alegria) de articulação das experiências. Arkhé não é o nostálgico antigo, nem qualquer apelo substancialista ao primal, mas aquilo que se subtrai às tentativas puramente racionais de apreensão, enquanto algo de fundamental de que não 
se recorda, que falta, mas que se simboliza no culto aos princípios cosmológicos (os orixás, as divindades) e aos ancestrais que presentificam os princípios inaugurais.

Em termos mais concretos, a memória da Arkhé consiste de um repertório cultural de invocações, saudações, cantigas, danças, comidas, lendas, parábolas e símbolos cosmológicos que se transmite iniciaticamente no quadro litúrgico do terreiro e, no âmbito da sociedade global, expande-se nas descrições e nas interpretações escritas ou livrescas.

\section{Considerações finais}

A reinterpretação brasileira do legado cultural inseriu-se historicamente na formação social brasileira para orientar os rumos civilizatórios do escravo e seus descendentes. Os símbolos, os desdobramentos culturais de um paradigma (a Arkhé africana, manifestada num sistema axiológico, em que se articulam valores éticos, cerimônias, sacrifícios e hierarquia) eram e são representações capazes de atuar como instrumentos dinâmicos no jogo social de estratos economicamente subalternos.

Os aspectos políticos dessa movimentação histórica costumam escapar à etnologia desavisada, geralmente centrada na descrição das tradições e dos ritos, como se fossem "sobrevivências" culturais, senão anacronismos místicos. Movidos pela pura lógica culturalista, muitos são os analistas que passam ao largo do papel político das reconstruções sígnicas (na forma de cânticos, rituais, danças, etc.), por não conseguirem enxergar uma posição historicamente diferenciada frente ao conflito entre o universalismo político do Estado e um particularismo cultural -- logo, a dificuldade de enxergar o livre-agir no imaginário ativo de um grupo econômica e socialmente subalterno.

Por isto, é no mínimo uma miopia analítica, e no máximo uma completa ingenuidade culturalista, supor que a problemática dos cultos afro-brasileiros se resolva apenas na dimensão simbólica -- aquela com que lida normalmente a antropologia. Ao lado dos fenômenos mítico-religiosos alinham-se pulsões de afirmação grupal, reivindicações de reconhecimento identitário e estratégias de poder (em torno da hegemonia das representações) que sugerem uma contra-hegemonia original.

Desta maneira, os cultos afro-brasileiros podem ser encarados, à luz da cultura tardo-moderna como lugares irradiadores de um agir coletivo, lastreado por valores e deveres comunitários, ao lado de novos tipos de ações grupais que incluem meios de comunicação, sindicatos e entidades civis, em busca de uma renovação das relações sociais.

Não se trata de nenhuma Realpolitik, ou seja, do jogo em torno da administração jurídico-constitucional dos dispositivos de poder, garantido pelo absolutismo da representação escrita, mas de um agir originário da oralidade, em que a existência do culto, como continuidade de outro paradigma civilizatório, é em si mesma uma forma particular de soberania, no interior de um território controlado pelos aparatos de um Estado nacional $\square$ FAMECOS

\section{NOTAS}

* Texto apresentado no X Seminário Internacional de Comunicação, PUCRS, novembro de 2009

1 As outras duas modalidades chamam-se Secondness (secundidade), que é a experiência determinada, material, conflitiva e vivida, e Thirdnesss (terceiridade) ou esfera da síntese, das conclusões gerais, do hábito e da aprendizagem, que permite pensar as outras categorias.

2 Bachelard, Gaston. L'Eau et les Rêves - essai sur l'imagination de la matière.Librairie José Corti, 1942, p. 2.

3 Ibidem, pp. 2-3.

4 Baudrillard, Jean. L'Échange Symbolique et la Mort. Gallimard, 1976, p. 205.

5 Cf. Bachelard, Gaston. Op. Cit., p. 24.

6 Evidentemente, este manejo da noção de imaginário como um repertório de imagens separado do real é próprio de uma sociologia da cultura. As várias disciplinas sociais ou humanas adequam o conceito a seu campo específico de conhecimento. Na teoria lacaniana da psicanálise, são imaginárias as representações das pulsões que, com o valor de significantes, se articulam com o simbólico e com o real para fundar o eu. Já na psicologia profunda de Jung, o imaginário é algo quase substancial e palpável em formas ou entidades (reais ou fictícias, segundo a classificação feita pelo utilitarista Bentham) universalmente produzidas por um inconsciente coletivo. Vale também lembrar Sartre, que empreendeu uma descrição fenomenológica do que chamava de "objetos imaginários", isto é, imagens mentais, manchas, figuras projetivas, retratos, etc. Hoje, há toda uma sociologia e uma antropologia do imaginário que, de algum modo, fazem repercutir academicamente a gnose junguiana.

7 Wais, Kurt. Le Roman d'Artiste: E.T.A. Hoffmann et Balzac. In La Littérature Narrative d'Imagination. Colloque de Strasbourg, PUF, 1961, p. 147.

8 Cf. Sercovich, A. El discurso, el psiquismo y el registro imaginário. Nueva Visión, 1977. 